\title{
Competencias emocionales de las futuras personas docentes: un estudio sobre los niveles de inteligencia emocional y empatía
}

Porras Carmona, Silvia; Pérez Dueñas, Carolina; Checa Fernández, Purificación; Luque Salas, Bárbara Competencias emocionales de las futuras personas docentes: un estudio sobre los niveles de inteligencia emocional y empatía

Revista Educación, vol. 44, núm. 2, 2020

Universidad de Costa Rica, Costa Rica

Disponible en: http://www.redalyc.org/articulo.oa?id=44062184014

DOI: https://doi.org/10.15517/revedu.v44i2.38438

Esta obra está bajo una Licencia Creative Commons Atribución-NoComercial-SinDerivar 3.0 Internacional. 


\section{Competencias emocionales de las futuras personas docentes: un estudio sobre los niveles de inteligencia emocional y empatía}

Emotional Competence among Future Teachers: A Study on Emotional Intelligence and Empathy Levels

Silvia Porras Carmona

Universidad de Córdoba, España

silpocar@gmail.com

iD http://orcid.org/0000-0001-6104-1429

Carolina Pérez Dueñas

Universidad de Córdoba, España

cpduenas@uco.es

(iD http://orcid.org/0000-0002-9991-2733

Purificación Checa Fernández

Universidad de Granada, España

checaal@ugr.es

(D) http://orcid.org/0000-0002-8360-1033

Bárbara Luque Salas

Universidad de Córdoba, España

bluque@uco.es

(iD http://orcid.org/0000-0001-6858-9892
DOI: https://doi.org/10.15517/revedu.v44i2.38438

Redalyc: http://www.redalyc.org/articulo.oa?id=44062184014

Recepción: 18 Septiembre 2019

Aprobación: 28 Abril 2020

\section{Resumen:}

La formación inicial y permanente del profesorado constituye una herramienta clave para lograr una enseñanza de calidad. Es necesario incluir en la formación de docentes el desarrollo de competencias socioemocionales para su futura práctica docente. El objetivo de este estudio es evaluar cómo percibe sus niveles de Inteligencia Emocional (IE) y Empatía el estudiantado universitario de primer y cuarto año en carreras de Educación y explorar si existen diferencias con otras titulaciones. La muestra estuvo constituida por 569 estudiantes de primer y último año de las carreras de Educación Infantil, Educación Primaria, Medicina y Química, quienes cumplimentaron la escala TMMS-24 para evaluar la IE y la escala IRI para evaluar la Empatía. Se elaboraron análisis de correlación y de covarianza. Los principales resultados en relación con los niveles de IE percibida muestran que el estudiantado de las carreras de Educación presenta mayores niveles de Atención Emocional a su ingreso y que el alumnado de cuarto año de Educación y Medicina presenta mayores niveles de Reparación y Claridad Emocional en comparación con los de primer año. Respecto a la Empatía, el estudiantado de Educación y Medicina denota mayores niveles percibidos de Preocupación Empática tanto en el momento de su ingreso como al finalizar la carrera. Los estudiantes de Educación, a diferencia de los de Medicina, no tuvieron mayores niveles de Toma de Perspectiva ni preocupación empática al finalizar sus estudios en comparación con los que ingresaron el primer año. Además, los niveles de Malestar Personal fueron mayores en las titulaciones de Educación y Química. Estos resultados reflejan la importancia de cambiar el currículo de las carreras de Educación para fomentar habilidades empáticas. Palabras ClaVe: Inteligencia Emocional, Empatía, Estudiantes Universitarios, Competencias Socioemocionales.

\section{Abstract:}

Initial and continuing education for teachers is an essential means for achieving quality teaching. Teacher training must include development of social-emotional competences that can be applied throughout their future teaching career. This study aims to assess how first and fourth year Education Majors perceive their own level of Emotional Intelligence (EI) ad Empathy and explore if there are any differences among other college majors. The sample used included 569 first- and fourth-year college students majoring in Preschool Education, Primary School Education, Medicine and Chemistry, who completed the Trait Meta-Mood Scale-24 
(TMMS-24) Scale for IE assessment and the Interpersonal Reactivity Index (IRI) to assess empathy. A correlation and covariance analysis were undertaken. The main results regarding perceived levels of EI, reveal that Education Majors had higher levels of emotional attention upon entering college and that fourth year Education and Medical students had higher levels of emotional clarity and repair compared to first-year students. Education and Medical students showed higher levels of perceived empathic concern both upon entering college as well as at the end of their college careers. Yet, students majoring in Education, unlike students majoring in Medicine, did not show a higher level of perspective taking or empathic concern upon finishing their studies compared to first year students. In addition, personal distress levels were higher among Education and Chemistry majors. These results reflect the importance of changing Education Major curriculums to foster the development of empathic skills.

KEYWORDS: Emotional Intelligence, Empathy, College Students, Social-emotional Competences.

\section{INTRODUCCIÓN}

Hasta finales del siglo pasado, la educación centraba su interés principalmente en los aspectos cognitivos, quedando reducidos al ámbito privado, lo social y emocional. En los últimos años, la escuela parece encaminarse no solo a enseñar a pensar, también a sentir, con el objetivo de lograr un desarrollo integral en el alumnado. Es más, de no ser así, se estaría obviando que lo emocional repercute en los procesos de enseñanzaaprendizaje.

Desde hace varias décadas las diversas leyes educativas propuestas en España han contemplado la necesidad de incluir la educación emocional en el currículo educativo. Para ello, profesionales de la docencia han de recibir la formación precisa que les permita conocer sus propias emociones, gestionarlas, y comprender e interesarse por los estados emocionales y sentimientos de su alumnado.

La formación inicial y permanente de las actuales y las futuras personas docentes conforma así una herramienta fundamental en el afán de conseguir una enseñanza de calidad. El desarrollo de esas competencias socioemocionales en los profesionales de la educación no solo va a repercutir en el aprendizaje del alumnado, sino también en el de ellos mismos, en su propio bienestar y en un mayor rendimiento laboral (Palomera, Fernández y Brackett, 2008). La educación de las emociones parece haberse convertido, por tanto, en prioridad y reto actual en los sistemas de enseñanza.

En una revisión de la literatura, efectuada por Extremera y Fernández (2004) sobre la influencia de la Inteligencia Emocional (en adelante IE) en el funcionamiento personal y social, se hace patente la necesidad de fomentar este tipo de educación, pues existe evidencia empírica la cual apoya que niños y niñas con mayor IE son menos agresivos y tienen comportamientos más prosociales (Extremera y Fernández, 2002; Extremera, 2003).

Tradicionalmente, ellos y ellas han sido socializados de diferente manera respecto al aspecto emocional, siendo notoria la relación femenina con este. Esa supuesta mayor sensibilidad de la mujer parece deberse a su tendencia a observar al otro, al modo en que familiares y educadores han tratado las emociones con ella y a la socialización diferencial que reciben niñas y niños desde el momento de nacer (Sánchez, Fernández, Montañés y Latorre, 2008). Padres y madres tienen un papel fundamental aquí, pues generalmente son los agentes socializadores principales y primeros de niños y niñas, con quienes deberían tratar las emociones de igual modo. Sin embargo, suele ser con ellas con las que tienden a expresar un mayor repertorio emocional, .los padres tienden a hablar más sobre emociones con sus hijas que con sus hijos. (Sánchez et al., 2008, p. 459), siendo ellos -en contraposición- socializados desde niños para reprimir esa manifestación de emociones. En este aspecto, en el que la educación emocional no es equitativa, es donde la educación tiene un papel fundamental para lograr una sociedad sin estereotipos de género y donde la formación de las actuales y las futuras personas docentes es clave para lograrlo.

Así, el desarrollo de la IE en contextos educativos ha ido cobrando cada vez mayor relevancia en las últimas décadas. Prueba de ello, es el creciente número de investigaciones al respecto, destacando entre ellas las relacionadas con los efectos beneficiosos de la educación y desarrollo de la IE entre estudiantes de distintas etapas educativas (Fernández y Extremera, 2004; Extremera y Fernández, 2006; Fernández 
y Ruíz, 2008; Bello, Rionda y Rodríguez, 2010; Chico, Moya, Seva y Piera, 2012; Salguero,Palomera, y Fernández, 2012; Castillo, Salguero, Fernández, y Balluerka, 2013; Cobos, Flujas, y Gómez, 2016; Eccles, Devis, y Mayer, 2017;Gómez, Mendoza, Paino, y de Matos,2017) y, concretamente, aquellas centradas en los estudiantes universitarios de ramas sociales y sanitarias (Austin,Evans, Goldwater, y Potter, 2005; Augusto,López, Martínez, y Pulido,2006; Augusto, López, Aguilar, y Salguero, 2009; Pena y Extremera, 2012; Vinod,Srivastava, y Raychaudhuri, 2012).

\section{MARCo TEÓRICO Y ESTADo DE LA CUESTIÓN}

El término IE fue introducido en la década de los 90 por Mayer y Salovey (1997). De acuerdo con estos autores, la IE es la habilidad de una persona para percibir -en sí misma y las demás-, expresar y regular las emociones adecuadamente, en otras palabras, se basa en el uso adaptativo de las emociones. Previamente, la teoría de las inteligencias múltiples propuesta por Gardner (1983), basada en la pluralidad como característica de la inteligencia y planteando que las personas pueden aprender y conocer el mundo de ocho maneras distintas, permitió comprender que las personas no solo poseen inteligencia cognitiva, sino que además cuentan con otras inteligencias que les permiten tomar decisiones, generar ideas, mejorar las relaciones interpersonales, etc. Todas ellas deberán ser tenidas en cuenta a la hora de desarrollar competencias en la escuela infantil y primaria. De entre todas estas formas de ser inteligente se encuentra la interpersonal e intrapersonal que conforman la llamada IE. La primera, siguiendo a Mayer y Salovey (1997), se entiende como la habilidad para reconocer, comprender y regular las emociones en las demás personas, y la segunda para orientar esas mismas habilidades a las propias emociones. De esta manera, la inteligencia interpersonal coincidiría con una forma de inteligencia más social y la inteligencia intrapersonal con una más personal y autorreflexiva (Bisquerra, 2003).

En la literatura se pueden distinguir dos modelos principales sobre IE: modelo mixto y modelo de habilidad.

El modelo mixto recoge una perspectiva muy amplia de IE. En este se tienen en cuenta rasgos de personalidad, competencias socioemocionales, aspectos motivacionales y habilidades cognitivas (Goleman, 1996).

Por otro lado, el modelo de habilidad se centra en aquellas habilidades cognitivas las cuales pueden ser entrenadas. Los principales representantes son Mayer y Salovey (1997). Dicho modelo, en el que se basa esta investigación, consta de cuatro habilidades básicas:

1. La percepción emocional es la destreza para identificar y reconocer los sentimientos, emociones, estados y sensaciones fisiológicas y cognitivas.

2. La facilitación o asimilación emocional es la habilidad que permite tener en cuenta los sentimientos cuando se trata un problema.

3. La comprensión emocional es la habilidad para comprender las señales emocionales, etiquetar y reconocer las emociones, así como conocer cómo se combinan las distintas emociones que hace que existan unas emociones secundarias.

4. Por último, la regulación emocional es la más compleja. Es la habilidad para estar abierto a los sentimientos, positivos y negativos, y reflexionar sobre estos para eliminar o aprovechar la información que sea útil.

La IE se mide mediante autoinformes, test de ejecución y los informes de observadores externos. Los dos primeros son los métodos más utilizados.

La principal ventaja de las medidas de autoinforme es que son cuestionarios que se administran de una manera fácil y rápida y se puede medir la percepción de las personas sobre sus niveles de IE. La persona debe señalar su grado de acuerdo o desacuerdo en cuanto a su capacidad de: percibir, atender, comprender, regular 
y manejar sus emociones. Para ello, Salovey y Mayer (1997) desarrollaron en la década de los 90 el Trait MetaMoodScale donde recogen los aspectos de IE intrapersonal de las personas. En España se ha desarrollado una versión modificada: TMMS-24 (Fernández et al., 2004).

Dentro del componente interpersonal, se destaca el constructo de empatía definido como la capacidad de comprender el estado de ánimo de otras personas y ponerse mentalmente en su lugar (Fernández, López, y Márquez,2008), englobando componentes de tipo cognitivo y de tipo emocional o afectivo (Mestre,Samper, y Frías2002; Arango, Clavijo, Puerta, y Sánchez, 2014; Carnicer y Calderón, 2014). Este aspecto resulta clave en la interacción social y -por consiguiente- en la formación de las futuras personas docentes (Fernández et al., 2008).

En este último aspecto, en la empatía, cabe destacar el papel de las llamadas neuronas espejo, las cuales permiten entender y comprender las emociones del otro "haciéndonos sentir lo que siente" (Celdrán y Ferrandíz, 2012, p.1325). Cuando las neuronas espejo no funcionan correctamente en una persona surge la posibilidad de dañar a otras personas sin que ello provoque malestar, pues estas tienen un mundo emocional que les impide ponerse en el lugar de otras personas y conmoverse del sufrimiento ajeno, es por ello por lo que ocuparse del mundo emocional resultaría clave para la prevención de posibles situaciones delictivas dentro del sistema educativo actual, tal y como defienden Cobos et al. (2016), Extremera y Fernández (2006) y Salguero et al. (2012).

Tanto la IE como la Empatía forman parte de las habilidades socioemocionales necesarias en la formación de los y las docentes. En estudios previos, ambos constructos parecen correlacionar de forma positiva (Fernández y Extremera, 2004; Augusto et al., 2009).

\section{JuSTIFICACIÓN}

De manera concreta y haciendo hincapié en la empatía, se encuentran diversos estudios los cuales muestran que dicha habilidad contribuye a una conducta más prosocial y cooperativa, a acciones altruistas, a la mejora de las relaciones interpersonales, a la autorregulación emocional y a la disminución de la agresividad (Mestre et al., 2002; Carnicer y Calderón, 2014). Por tanto, la educación emocional se muestra como un modo eficaz de prevención, como una herramienta para enseñar a gestionar las situaciones que supongan un riesgo para las personas (Bello et al., 2010).

La necesidad de incluir la educación emocional como parte fundamental para el desarrollo integral de niños y niñas, se contempla en España -desde hace varias décadas- en las diversas leyes educativas, que apuestan por un currículo educativo que contemple dicha educación emocional. Por ello, las personas docentes han de recibir previamente la formación precisa en sus carreras, conocer sus propias emociones, gestionarlas, y comprender e interesarse por los estados emocionales y sentimientos de sus estudiantes. Esto es, desarrollar su IE. Solo de esta manera podrán adquirir las competencias necesarias para enseñar -a su vez-a su alumnado a detectarlas en sí mismo y en las demás personas, sirviendo así de ejemplo (Eccles et al., 2017).

Haciendo referencia a la normativa vigente española, de acuerdo con el Ministerio de Educación y Ciencia de España (2007), se establecen los requisitos para la verificación de los títulos universitarios oficiales que habiliten para el ejercicio de la profesión de Maestro/Maestra de Educación Infantil y Primaria respectivamente-, entre las competencias que han de adquirir se destaca que se deben "mostrar habilidades sociales para entender a las familias y hacerse entender por ellas" (p. 53749), "promover y facilitar los aprendizajes en la primera infancia desde una perspectiva globalizadora e integradora de las distintas dimensiones cognitiva, emocional, psicomotora y volitiva” (p. 53736) y “[...] promover la autonomía y singularidad de cada estudiante como factores de educación de las emociones, sentimientos y valores en la primera infancia" (p.53736). De igual modo, en el marco de la Unión Europea -en concreto Kwan, MacLeod, Chandler y Fox (2017)- establecen que existen ciertas competencias clave a desarrollar para lograr un efectivo 
"lifelong learning" (p. 19), entre ellas destacan las competencias sociales y civicas, unidas a conceptos tales como gestión emocional, empatía y relaciones interpersonales, entre otros.

Por ello, y de acuerdo con la legislación, las habilidades en IE se deberán ver incrementadas en los egresados de las titulaciones en educación. Del mismo modo, en la carrera de Medicina se concreta la importancia de adquirir esas habilidades emocionales en la competencia básica de transmitir información, ideas, problemas y soluciones y que sepan comunicar sus conclusiones, la transversal habilidades interpersonales y las específicas de conocer los aspectos de la comunicación con pacientes, familiares y su entorno social, aprender a dar malas noticias, pronósticos y consejo terapéutico y conocer los fundamentos del desarrollo cognitivo, emocional y psicosocial en la infancia y adolescencia. Sin embargo, en el grado de química se comprueba que el plan de estudio no contempla competencias que trabajen las habilidades emocionales antes mencionadas

En relación con las carreras de Educación y Medicina y otras, algunos estudios como el de Augusto et al. (2006; 2009), Palomera et al., (2008) o Vinod et al. (2012), entre otros, han destacado cómo influye el desarrollo de la IE en estudiantes de Medicina, estudiantes de Enfermería o en Docentes en relación con el rendimiento académico o con la satisfacción vital. Sin embargo, según se conoce no hay estudios que evalúen el nivel de estas habilidades emocionales en estudiantes de primer y último curso, comparando además entre varias titulaciones con contenidos curriculares en las cuales se incluyan habilidades emocionales y otras en las que no se incluyan.

Este estudio evalúa el nivel percibido de IE y Empatía que los estudiantes de las carreras de Educación tienen al decidir comenzar esta formación y en el último año, haciendo una comparativa con los estudiantes de otras carreras, en las que también se incluye en su currículo formación en habilidades emocionales como Medicina, y otras carreras en las que no se incluye, como Química.

Así, el objetivo de este trabajo irá orientado a explorar los niveles de competencia emocional percibida de las futuras personas docentes de primer y último año de carrera en comparación con estudiantes de otras titulaciones, Medicina y Química. En particular, las habilidades de IE intrapersonal y la Empatía y la correlación entre ambas. Para evaluar las diferencias entre el alumnado de primer y último curso de las carreras de Educación, Medicina y Química, se introdujo una pregunta en el cuestionario sobre si habían recibido o no formación previa en IE al inicio de la carrera, incluyendo así la variable formación previa en IE en el estudio.

Consideramos, al igual que Arango et al. (2014), que los estudiantes que cursan una carrera de Educación tendrán una responsabilidad social cuando comiencen a desempeñar la profesión a la que aspiran. De ahí la relevancia de indagar si al finalizar su titulación se perciben con un mejor nivel desarrollo de habilidades socioemocionales tan importantes como la IE y la Empatía.

Así, de acuerdo con lo expuesto, los objetivos planteados en este estudio son las siguientes:

1. Comprobar la existencia de correlaciones estadísticamente significativas entre las dimensiones de los instrumentos empleados.

2. Conocer los niveles de empatía e IE percibida de los participantes.

3. Establecer la existencia de diferencias estadísticamente significativas entre las variables género, curso y titulación, y cada una de las dimensiones de la IE percibida y de la empatía.

\section{MÉTODo}

El estudio se elaboró desde un enfoque metodológico cuantitativo basado en un diseño transversal para identificar las diferencias en los niveles de IE percibida entre el estudiantado de las carreras de Educación, Medicina y Química de primer y último curso de sus respectivas carreras. De esta manera, se podrán identificar diferencias en los niveles de IE percibida y Empatía del estudiantado que accede a su primer año de carrera y a su término. 


\section{Participantes}

La muestra está formada por 569 estudiantes universitarios de la Facultad de Ciencias de la Educación, Facultad de Medicina y Enfermería y Facultad de Ciencias, todas de la Universidad de Córdoba, España. La distribución de la muestra responde a las características de la población: en las carreras de la Educación hay siete grupos (cuatro en Educación primaria y tres en Educación infantil) y en las carreras de Medicina y Química, un solo grupo por titulación.

El grupo de estudiantes del área de educación está formado por 452 estudiantes, siendo 359 mujeres (79,4\%) y 93 hombres (20,6\%). La edad estuvo comprendida entre 18 y 42 años, con una edad media de 21,47 años. Se distribuyen en dos titulaciones: $176(38,9 \%)$ estudiantes en la carrera de Educación infantil (110 de primer curso y 66 de cuarto) y $276(61,1 \%)$ en la carrera de Educación primaria (127 de primer curso y 149 de cuarto). Del mismo modo se indagó en otros datos sociodemográficos de interés, como son la vocación de los y las estudiantes y la formación previa recibida o no en IE. Del total, 397 personas (87,8\%) eligieron, como primera opción la carrera de Educación Infantil o Primaria frente a 51 (11,3\%) que no lo hicieron en primera opción y $4(0,9 \%)$ que no contestaron. Por otro lado, 260 personas $(57,5 \%)$ afirmaron haber recibido formación previa al inicio de la carrera en IE frente a 186 (41.2\%) que negaron haberla recibido y 6 (1,3\%) que no respondieron.

El grupo de estudiantes de la carrera de Medicina está formado por 50 estudiantes, siendo 29 mujeres (58\%) y 21 hombres (42\%). La edad estuvo comprendida entre 17 y 26 años, con una edad media de 19.84 . De primer curso eran 24 estudiantes (48\%) y de cuarto curso 26 (52\%). Por otro lado, la mayoría eligieron de primera opción la carrera de Medicina, 46 personas (92\%) frente a 1 (2\%) y 3 que no respondieron (6\%). Afirmaron haber recibido formación previa al iniciar su carrera en IE 16 estudiantes (32\%) frente a 34 que negaron haberla recibido (68\%).

El grupo de estudiantes de la carrera de Química está formado por 67 estudiantes, 40 mujeres $(59,7 \%)$ y 27 hombres (40,3\%), cuya edad media era de 19.30 (edad comprendida entre 17 y 36 años). De primer curso 46 estudiantes $(68,7 \%)$ y de cuarto $21(31,3 \%)$. De estas, 39 personas afirmaron haber elegido la carrera de Química como primera opción $(58,2 \%)$ y 28 aseguraron no haberlo hecho $(41,8 \%)$. La mayoría negó haber recibido formación previa en IE: 63 personas (94\%) frente a 4 (6\%).

\section{INSTRUMENTOS}

La escala TMMS-24 (Fernández y Extremera, 2004) es una medida de autoinforme reducida, modificada y adaptada a la cultura española. Consta de 24 ítems en la que las personas participantes deben indicar el grado de acuerdo o desacuerdo con cada una de las afirmaciones usando una escala tipo Likert de cinco puntos (desde 1 = nada de acuerdo a 5 = totalmente de acuerdo). Un ejemplo de estos ítems es: a menudo pienso en mis sentimientos (ítem 7). Está dividida en tres factores o subescalas que evalúan la Atención a los sentimientos, la Claridad emocional y la Reparación de las emociones, todas ellas evaluadas por 8 ítems. La consistencia interna de cada una de las subescalas fue superior a .85 (.90 en atención, .90 en claridad y .86 en reparación), siendo así el alfa de Cronbach por encima de .85 (Extremera y Fernández, 2005). Como puede apreciarse en la literatura, su uso está muy extendido (Augusto et al., 2006; Chico et al., 2012; Cobos et al., 2016; Extremera y Fernández, 2006; Extremera, Durán, y Rey,2007; Salguero et al., 2012).

Por otro lado, la escala Interpersonal Reactivity Index (IRI) de Davis (1980) es una de las medidas de autoinforme más utilizadas para evaluar los aspectos cognitivos y emocionales de la actitud empática (Besel y Yuille, 2010). Se trata de una escala tipo Likert en la cual las personas participantes deben indicar el grado en que las afirmaciones les describen por medio de cinco opciones (desde $1=$ no me describe bien a 5 $=$ me describe muy bien). Un ejemplo de estos ítems es: cuando estoy disgustado con alguien normalmente intento ponerme en su lugar por un momento (ítem 25), consta además de 28 ítems distribuidos en cuatro 
subescalas: Toma de Perspectiva, Fantasía, Preocupación Empática y Malestar Personal. La fiabilidad y validez se examinó en un estudio de Pérez, De Paúl, Etxeberría, Montes y Torres (2003) y fue de: .75 para Toma de Perspectiva, .80 para Fantasía .71 para Preocupación Empática y para Malestar Personal. Esta escala, como puede comprobarse, ha sido utilizada en numerosos estudios (Arango et al., 2014; Besel y Yuille, 2010; Castillo et al., 2013; Delič, Novak, Kovačič, y Avsec, 2011; Fernández et al., 2008; Mestre et al., 2002).

\section{Procedimiento}

El proceso de cumplimentación tuvo lugar en la Facultad de Ciencias de la Educación, Facultad de Medicina y Enfermería y Facultad de Ciencias, todas de la Universidad de Córdoba (España) en colaboración con el profesorado de cada una de las carreras, quienes facilitaron el acceso a su alumnado en los primeros o últimos 15 minutos de docencia en las carreras de Educación Primaria, carrera de Educación Infantil, carrera de Medicina y carrera de Química. A cada participante se le proporcionó una hoja de consentimiento, donde se les informó del propósito del estudio y el carácter voluntario del mismo, dejando el tiempo necesario para su lectura y firma, además de la posibilidad de aclarar cualquier duda que se plantease. Seguidamente, rellenaron un cuadernillo con los datos sociodemográficos y los cuestionarios descritos previamente. Conforme lo iban completando se lo entregaban al investigador, el cual asignó un código a cada uno para asegurar su confidencialidad.

\section{ANÁLISIS DE DATOS}

Para poner a prueba los objetivos, se desarrollaron dos tipos de análisis. En primer lugar, análisis de correlación de Pearson para investigar la relación entre IE y Empatía. Posteriormente, análisis ANCOVA para cada una de las variables de IE y Empatía en función del curso (primero y cuarto) y la titulación (carrera de Educación, carrera de Medicina y carrera de Química) como factores de grupo y la formación previa en IE como covariable.

\section{Resultados}

Para comprobar las diferencias entre ambos sexos se elaboraron análisis de varianza para cada uno de los factores de los dos cuestionarios evaluados (TMMS-24 e IRI). Se puede afirmar que, en general, en el TMMS-24 no se encontraron diferencias significativas entre ambos sexos. Tan solo destacar que en el factor de reparación emocional se han encontrado diferencias significativas $F_{(1.450)}=21.97, p<.05$, de manera que los hombres presentan un mejor índice de reparación emocional que las mujeres $\left(M_{\text {hombre }}=30.04 ; M_{\text {mujer }}=\right.$ 26.51). Sin embargo en el IRI se hallaron diferencias significativas para el factor de fantasía $F(1.450)=16.80$, $p<.05\left(M_{\text {hombre }}=21.49 ; M_{\text {mujer }}=24.01\right)$, el de preocupación empática $F_{(1.450)}=39.39, p<.05\left(M_{\text {hombre }}=\right.$ $\left.24.90 ; M_{\text {mujer }}=27.82\right)$ y el de malestar personal $F_{(1.450)}=12.15, p<.05\left(M_{\text {bombre }}=17.86 ; M_{\text {mujer }}=19.69\right)$, siendo en todos ellos las mujeres las que presentan un mejor índice en comparación con los hombres.

La Tabla 1 Correlaciones y estadisticos descriptivos presenta las medias y desviaciones típicas para cada una de las variables y correlaciones entre ellas. Los resultados mostraron las correlaciones positivas entre el factor Atención y cada uno de los factores de la escala de Empatía; entre el factor Claridad y Toma de Perspectiva, Fantasía y Preocupación Empática, y entre Reparación y Toma de Perspectiva, Fantasía y Preocupación Empática. 
TABLA 1

Correlaciones y estadísticos descriptivos

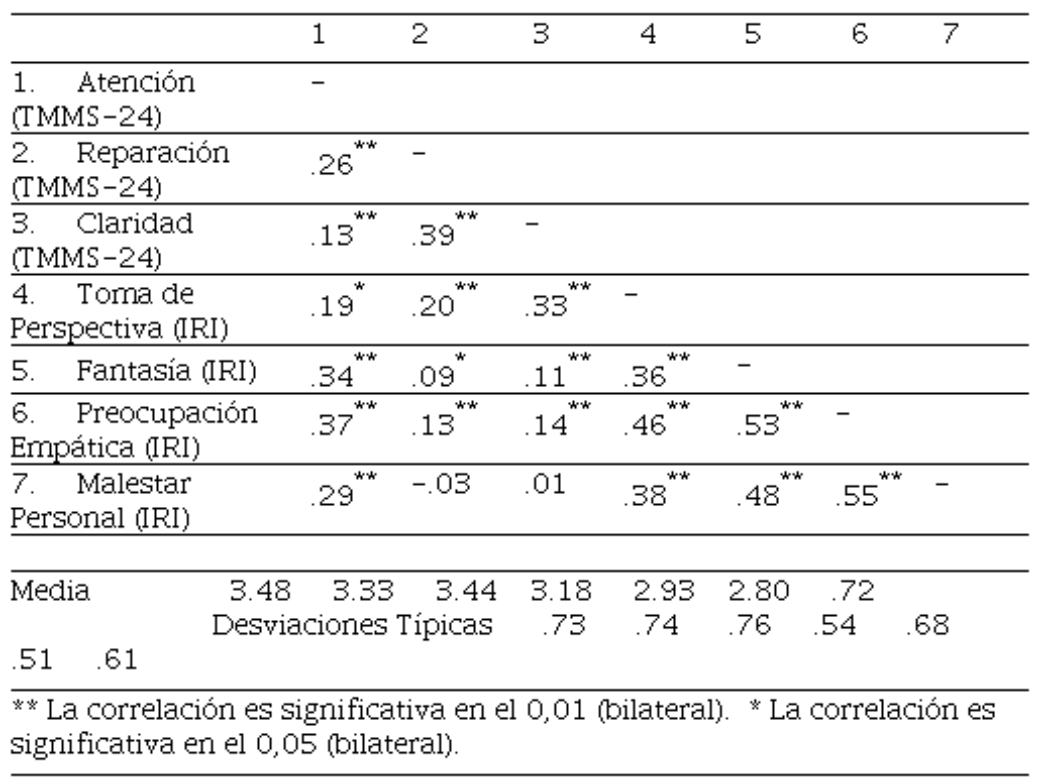

Fuente: Elaboración propia.

Para evaluar el segundo y tercer objetivo, se ejecutó análisis ANCOVA para cada una de las variables de IE y empatía en función del año (primero y cuarto) y la titulación (carrera de Educación, carrera de Medicina y carrera de Química) como factores de grupo y la formación previa en IE como covariable, para controlar que este último factor no estuviese influyendo en las diferencias entre las distintas titulaciones y curso.

El ANCOVA para el factor de Atención muestra un efecto principal de titulación $\mathrm{F}(2,562)=7.87$, $\mathrm{p}<.01$. Las comparaciones planeadas revelaron diferencias significativas entre estudiantes de Ciencias de la Educación (28.21) y Química (25.32) F(1,562)=12.85, p<.01, Ciencias de la Educación y Medicina (26.43) $\mathrm{F}(1,562)=4.29, \mathrm{p}<.05$ pero no hubo diferencias significativas entre Medicina (26.43) y Química (25.32) $\mathrm{F}(1,562)<1$. Se observan mayores niveles de Atención en estudiantes que cursan Ciencias de la Educación en comparación con el estudiantado que cursa las carreras de Medicina y Química.

El ANCOVA para el factor de Claridad muestra un efecto principal de titulación $\mathrm{F}(2,562)=8.97, \mathrm{p}<.01$. Las comparaciones planeadas revelaron que había diferencias estadísticamente significativas entre Ciencias de la Educación (26.87) y Química (23.55) $\mathrm{F}(1,56)=16.81$, p <.01y diferencias marginales entre Química (23.55) y Medicina (25.58) $\mathrm{F}(1,562)=3.29, \mathrm{p}=.07$. Sin embargo, no hubo diferencias entre las de Ciencias de la Educación y Medicina $\mathrm{F}(1,562)=2.23, \mathrm{p}=.13$. Y una interacción significativa entre el año y la titulación $\mathrm{F}(2,562)=2.88, \mathrm{p}<.05$.

Por otro lado, las comparaciones planeadas revelaron diferencias estadísticamente significativas entre el primer y último año de Ciencias de la Educación (primer año: 26.20; último año: 27.54$)(\mathrm{F}(1,562)=5.98$, $\mathrm{p}<.01$ ) y Medicina (primer año: 23.73; último año: 27.43) $\mathrm{F}(1,562)=5,09, \mathrm{p}<.01$, pero no hubo diferencias entre los cursos de la carrera de Química (primer curso: 24.35; último curso: 22.74) $\mathrm{F}(1,562)<1$. Se observan mayores niveles de Claridad emocional en los estudiantes de cuarto curso en comparación con los de primero en carreras de Educación y Medicina, pero no en las de Química.

El ANCOVA para el factor de Reparación muestra un efecto principal de año $\mathrm{F}(1,562)=5.53$, $\mathrm{p}<.01$.El alumnado de último año obtuvo una puntuación más alta en Reparación (28.31)en comparación con el de primer año (26.42) y una interacción significativa entre año y titulación $F(2,562)=3.77$, $p<.05$. Las 
comparaciones planeadas revelaron diferencias estadísticamente significativas entre el primer y último año en Ciencias de la Educación (primer año: 26.74; último año: 28.09) $(\mathrm{F}(1,562)=5.64$, p<.01) y Medicina (primer año: 25.23; último año: 30.55$) \mathrm{F}(1,562)=9.74, \mathrm{p}<.01$, pero no hubo diferencias entre los años en la titulación de Química (primer año: 27.28; último año: 26.27) $\mathrm{F}(1,562)<1$.Se observan mayores niveles de Reparación emocional en los estudiantes de cuarto año en comparación con los de primero en las carreras de Educación y Medicina, pero no en las de Química.

En la Figura 1 se pueden observar las diferencias descritas que hay en el nivel de los factores de Atención, Claridad y Reparación Emocional del estudiantado de las carreras de Educación, Medicina y Química para el primer y último año de carrera.

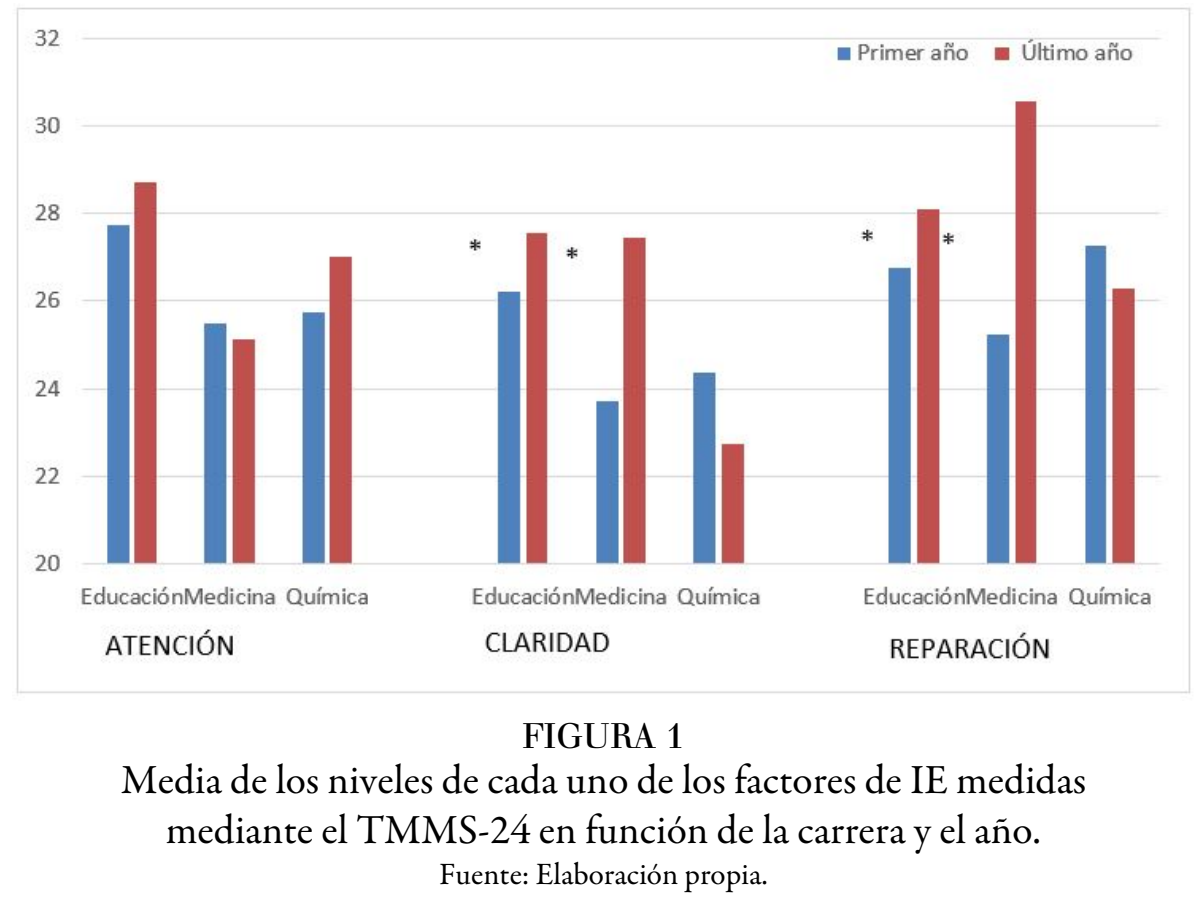

Respecto a la Empatía, el ANCOVA para el factor Toma de Perspectiva muestra un efecto marginal de titulación $\mathrm{F}(2,562)=2.84 \mathrm{p}=.06$. Las comparaciones planeadas relevaron diferencias estadísticamente significativas entre Química (24.15) y Medicina (26.12) $\mathrm{F}(1,562)=5.66, \mathrm{p}<.01$, pero no hubo diferencias entre Ciencias de la Educación (25.10) y Química $(24.15) \mathrm{F}(1,562)=2.26, \mathrm{p}=.11$, y entre Ciencias de la Educación (25.10) y Medicina (26.12) $\mathrm{F}(1,562)=2.48$, p=.11.

Por otro lado, las comparaciones planeadas revelaron diferencias estadísticamente significativas entre el primer y último año de Medicina (primer año: 24.83; último año: 27.42$)(\mathrm{F}(1,562)=4.62, \mathrm{p}<.01)$, pero no hubo diferencias entre los cursos de la carrera de Educación (primer curso: 24.87; último curso: 25.32) $\mathrm{F}(1,562)=1.29, \mathrm{p}=.25$, ni de Química (primer curso: 24.28; último curso: 24.04) $\mathrm{F}(1,562)<1$. Los datos reflejan que el alumnado de último año de Medicina tiene mayores niveles de Toma de Perspectiva que el estudiantado de último año de las carreras de Educación y Química $\mathrm{F}(1,562)=8.02$, p <.01.

El ANCOVA para el factor Fantasía muestra un efecto marginal de titulación $\mathrm{F}(2,562)=2.35, \mathrm{p}=.09$. Las comparaciones planeadas revelaron diferencias estadísticamente significativas entre Química (22.76) y Medicina (25) $\mathrm{F}(1,562)=4.44, \mathrm{p}<, 05 \mathrm{y}$ diferencias marginales entre Ciencias de la Educación (23.49) y Medicina (25) $\mathrm{F}(1,562)=3.37, \mathrm{p}=.07$, pero no hubo diferencias entre Ciencias de la Educación (23.49) y Química (22.76) $\mathrm{F}(1,562)<1$.

El ANCOVA para el factor de Preocupación Empática muestra un efecto principal de titulación $\mathrm{F}(2$, $562)=3.64, \mathrm{p}<.05$. Las comparaciones planeadas revelaron diferencias estadísticamente significativas entre Ciencias de la Educación (27.21) y Química (25.82) $\mathrm{F}(1,56)=5.41, \mathrm{p}<.05$ y entre Química (25.82) y 
Medicina (27.92) $\mathrm{F}(1,562)=6.45, \mathrm{p}<.01$, pero no hubo diferencias entre Ciencias de la Educación (27.21) y Medicina (27.92) $\mathrm{F}(1,562)=1.23, \mathrm{p}=.27$. Y una interacción marginal entre año y titulación $\mathrm{F}(2,562)=$ 2.69, $\mathrm{p}=.07$. Las comparaciones planeadas revelaron diferencias marginales entre los cursos para Química (primer año: 26.84; último año: 24.81) $(\mathrm{F}(1,562)=3.29, \mathrm{p}=.07)$, pero no hubo diferencias entre los años para Ciencias de la Educación (primer año: 27.48 ; último año: 26.95) $(\mathrm{F}(1,562)=1.74, \mathrm{p}=.19)$ y para Medicina (primer año: 27.04; último año: 28.8$)(\mathrm{F}(1,562)=2.14, \mathrm{p}=.14)$.

El ANCOVA para el factor Malestar Personal muestra un efecto principal de titulación $\mathrm{F}(2,562)=8.16$, $\mathrm{p}<.01$. Las comparaciones planeadas revelaron diferencias estadísticamente significativas entre Ciencias de la Educación (19.31) y Medicina (16.44) $\mathrm{F}(1,562)=16.3$, p<.01y entre Química (19.12) y Medicina (16.44) $\mathrm{F}(1,562)=8.5, \mathrm{p}<.01$, pero no hubo diferencias entre Ciencias de la Educación (19.31) y Química (19.12), $F(1,562)<1$. $Y$ un efecto marginal de año $F(1,562)=2.99, p=.08$.

En la Figura 2. se pueden observar las diferencias descritas que hay en el nivel de los factores de Atención, Claridad y Reparación Emocional del estudiantado de las carreras de Educación, Medicina y Química para el primer y último año de carrera.

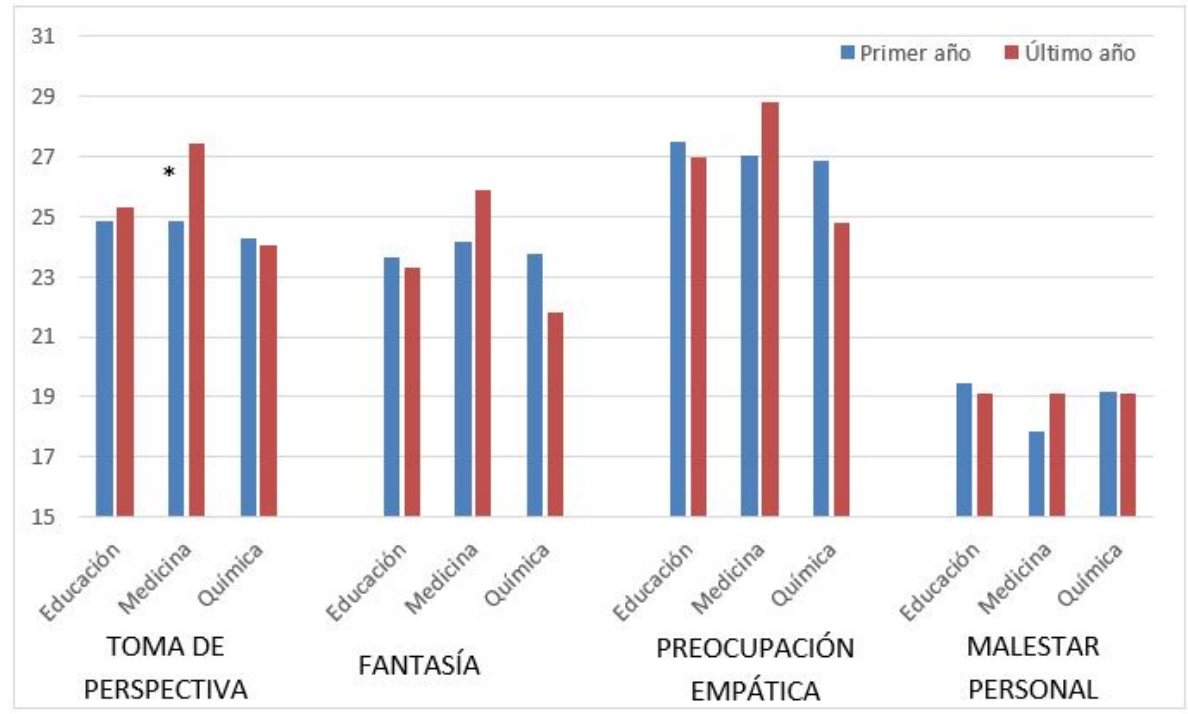

FIGURA 2

Media de los niveles de cada uno de los factores de empatía medidas mediante el IRI en función de la carrera y el año.

Fuente: Elaboración propia.

\section{Conclusiones}

De acuerdo con trabajos previos como los de Fernández y Extremera, (2004) y Augusto et al. (2009), existe una alta correlación positiva entre los niveles de los factores de Atención, Claridad y Reparación de la IE y los distintos factores que se incluyen en la Empatía, excepto en el factor de Malestar Personal, donde se puede observar una correlación positiva solo con los factores de Atención, pero no con los factores de Claridad y Reparación. Como indica la literatura, puntuaciones altas en Claridad y Reparación y medias en Atención definen a una persona con alta IE (Extremera y Fernández, 2005; Pérez, Unguetti, Castillo, y Acosta, 2006). En estudios previos, altos niveles de IE correlacionaban positivamente con el factor de Toma de Perspectiva y negativamente con el factor de Malestar Personal (Fernández y Extremera, 2004). Así, los resultados obtenidos en esta investigación estarían en línea con investigaciones previas indicando que estudiantado con niveles altos en las habilidades de claridad y reparación emocional tiene altos niveles de 
empatía, pero no correlaciona con los niveles de malestar personal. Sin embargo, participantes que presentan una elevada atención a las emociones presentan mayor malestar personal.

Estos datos van en la línea de estudios previos que indican que un alto nivel de atención a los sentimientos no sería adecuado para el bienestar de las personas (Extremera y Fernández, 2005; Pérez et al., 2006), ya que les produce un elevado malestar personal cuando empatizan con otros individuos.

Respecto al segundo objetivo, los resultados indican mayores niveles de Atención a las emociones en los estudiantes de las carreras de Educación en comparación con los de Química y Medicina. Estas diferencias no se deben al currículo, ya que se encuentran tanto al inicio como al finalizar la carrera, por lo que estas diferencias son debidas a otros factores que pueden estar incidiendo en el desarrollo de las habilidades socioemocionales de las futuras personas docentes. Estos datos se han de tener en cuenta como perfil de ingreso de estudiantes a estas carreras, ya que, como se acaba de exponer, niveles altos en atención emocional no sería adecuado para el bienestar personal. Puede ser que esta mayor atención esté relacionada con el desajuste emocional propio del fenómeno burnout que experimentan en mayor medida los docentes en relación con otros profesionales (Extremera, Fernández, y Durán, 2003; Extremera et al., 2007). Sería interesante que futuros estudios pusieran a prueba esta hipótesis.

En relación con los factores de Claridad y Reparación, es de destacar que los estudiantes de Educación y Medicina de cuarto año en comparación con los de primer año, presentan mejores niveles de Claridad y Reparación emocional, indicando que el alumnado que termina estas carreras presenta mejores niveles de IE percibida, que aquel que empieza. Sin embargo, esto no ocurre con las personas que estudian Química.

Por otro lado, teniendo en cuenta que en la muestra predominaba sustancialmente el sexo femenino, se puede afirmar que las mujeres no tienen un índice mayor de IE percibido que los hombres, es más, ellos puntúan más alto en el factor reparación emocional que ellas. Un dato sin duda llamativo considerando la creencia tradicional de acuerdo a las mujeres como seres más emocionales.

Por último, en relación con la Empatía, solo el estudiantado de cuarto curso de Medicina tuvo mayores niveles de Toma de Perspectiva empática que los de primer curso de Medicina y que estudiantes tanto de primer curso como los de cuarto de Educación y Química. Así, se concluye que, se debe estudiar la modificación del currículo de la carrera de Educación para conseguir fortalecer las habilidades de Toma de Perspectiva Empática, de acuerdo con los objetivos del currículo propuesto. Además, tanto los estudiantes de nuevo ingreso como los del último curso de carrera de Educación y Medicina, mostraron mayores niveles de Preocupación Empática que los estudiantes de Química. Este hecho debe ser tenido en cuenta para el futuro desarrollo del currículo del estudiantado de Educación y Medicina, ya que, si no se trabaja el adecuado desenganche emocional ante situaciones relevantes en la práctica profesional puede aparecer una sobrecarga para el docente y el médico. Por último, los mayores niveles de Malestar Personal en los estudiantes las carreras de Educación en comparación con los de Medicina, deben ser tenidos en cuenta para desarrollar actuaciones en los estudios de formación de futuras personas docentes y disminuirlos, de manera que no incidan en el malestar de los y las profesionales.

De acuerdo con este estudio, destacar la importancia de contemplar las dimensiones de IE y Empatía, pues no siempre un buen desarrollo de IE implica un buen nivel de empatía.

Para finalizar, señalar algunas sugerencias de estudio futuras. En primer lugar, dado que las medidas usadas para medir Empatía e IE son medidas de autoinforme, sería interesante para líneas de investigación futuras, complementar los resultados con medidas de desempeño como por ejemplo el MSCEIT (Mayer-SaloveyCarusoEmotionalIntelligence Test), para evitar que la menor o mayor auto-percepción de las habilidades emocionales de los sujetos pueda interferir en los resultados (Sánchez et al., 2008). Se podría considerar igualmente elaborar un estudio cuasi-experimental aplicando un programa de mejora de las competencias emocionales en el alumnado de ciencias de la Educación (objeto del estudio), prestando especial atención a dimensiones como la empatía. Del mismo modo, se considera atractivo comprobar si los futuros maestros y maestras apuestan o no, en su desempeño profesional, por desarrollar en su alumnado el conjunto de 
habilidades que engloban la IE que han adquirido durante su periodo de formación. Además, se recomienda evaluar estas habilidades emocionales en otras universidades y ejecutar un estudio transcultural y ver las diferencias entre distintos centros de formación de profesorado y la implementación del currículo en distintos organismos para mejorar el desarrollo de las habilidades socioemocionales. Por último, sería de especial relevancia hacer un estudio longitudinal, en vez de transversal como el que presentamos, para poder ver los efectos de cursar una titulación u otra en la misma muestra.

En resumen, se ha evidenciado con este estudio, que estudiantes de Educación y Medicina que acaban la carrera se perciben con mejores habilidades de Claridad y Reparación Emocional que quienes comienzan, pudiendo así decir, que tienen una mejor percepción de sus habilidades emocionales intrapersonales. Sin embargo, esto no sucede con las habilidades interpersonales como es la Empatía. A raíz de este trabajo, se debería de ser conscientes de la necesidad de trabajar de manera más sistemática las competencias emocionales interpersonales. Tras comparar estos datos con los obtenidos en los y las estudiantes de la carrera de Química se puede hipotetizar que la rama social y el contacto directo con personas en ella favorecen el desarrollo de la IE en los y las estudiantes. Arango et al. (2014) defienden al respecto que "los estudiantes del área de Ciencias Sociales y Humanidades tienen una mayor frecuencia de comportamientos socialmente responsables".p.93). Sin embargo, estudios adicionales se deberían desarrollar para poner a prueba esta hipótesis.

Este último aspecto sería muy positivo para la sociedad en su conjunto, pues estos serán los maestros y maestras del mañana encargados no solo de formar académicamente a los niños y niñas, sino también de hacerlo emocionalmente. La escuela, sin olvidar a la familia, debe convertirse en el lugar idóneo donde trabajar las habilidades interpersonales y desarrollar desde la infancia las competencias socioemocionales que logren obtener personas adultas equilibradas y competentes emocionalmente, para lo cual es necesario invertir en la formación del futuro profesorado. No se debe olvidar que "la educación de la inteligencia emocional se inserta en la convocatoria de educar para la vida" (Bello et al., 2010, p.43) y que esta ha de convertirse en una prioridad desde la infancia para lograr una sociedad progresivamente más sana y feliz.

\section{ReFERENCIAS}

Arango, O., Clavijo, S., Puerta, I. y Sánchez, J. (2014). Formación académica, valores, empatía y comportamientos socialmente responsables en estudiantes universitarios. Revista de la Educación Superior, 169, 89-105. doi: http s://doi.org/10.1016/j.resu.2015.01.003

Augusto, J., López, E., Aguilar, M. y Salguero, M. (2009). Predictive validity of perceived emotional intelligence on nursing students' self-concept. Nurse Education Today, 29(7), 801-808. doi: https://doi.org/10.1016/j.nedt.2 009.04 .004

Augusto, J., López, E., Martínez, R. y Pulido, M. (2006). Perceived emotional intelligence and life satisfaction among university teachers. Psicothema, 18, 152-157. Recuperado de https://www.redalyc.org/pdf/727/72709523.pdf

Austin, E., Evans, P., Goldwater, R. y Potter, V. (2005). A preliminary study of emotional intelligence, empathy and exam performance in first year medical students. Personality and Individual Differences, 39(8), 1395-1405. doi: https://doi.org/10.1016/j.paid.2005.04.014

Bello, Z., Rionda, H. y Rodríguez, M. (2010). La inteligencia emocional y su educación. Revista Cientifico-Metodológica, 51, 36-43. Recuperado de https://www.redalyc.org/pdf/3606/360635569006.pdf

Besel, L.y Yuille, J. (2010). Individual differences in empathy: The role of facial expression recognition. Personality and Individual Differences, 49(2), 107-112. Recuperado de https://www.redalyc.org/pdf/3606/360635569006.pdf

Bisquerra, R. (2003). Educación emocional y competencias básicas para la vida. Revista de investigación educativa, 21(1), 7-43. Recuperado de https://revistas.um.es/rie/article/view/99071

Carnicer, J. y Calderón, C. (2014). Empathy and Coping Strategies as Predictors of Well-being in Spanish University Students. Electronic Journal of Research in Educational Psychology, 12(1), 129-146. Recuperado de http://hdl.h andle.net/2445/128043 
Castillo, R., Salguero, J., Fernández, P. y Balluerka, N. (2013). Effects of an emotional intelligence intervention on aggression and empathy among adolescents. Journal of adolescence, 36(5), 883-892. doi: https://doi.org/10.101 6/j.adolescence.2013.07.001

Celdrán, J. y Ferrandíz, C. (2012). Reconocimiento de emociones en niños de Educación Primaria: Eficacia de un programa educativo para reconocer emociones. Electronic Journal of Research in Educational Psychology, 10(3), 1321-1342.Recuperado de http://repositorio.ual.es/bitstream/handle/10835/1908/Art_28_718.pdf?sequenc $\mathrm{e}=1$

Chico, E., Moya, M., Seva, U. y Piera, P. (2012). Incremental validity of Emotional Intelligence Perceived in predicting well-being. Anuario de psicología, 41(1), 123-134. Recuperado de http://revistes.ub.edu/index.php/Anuario-p sicologia/article/view/8241/10159

Cobos, L., Flujas, J. y Gómez, I. (2016). The role of Emotional Intelligence in Psychological Adjustment among Adolescents. Anales de Psicología, 33(1), 66-73. Recuperado de https://bit.ly/2TSuO7M

Davis, M.(1980). A multidimensional approach to individual differences in empathy. Catalog of Selected Documents in Psychology, 10(85), 1-17. Recuperado de https://www.uv.es/friasnav/Davis_1980.pdf

Delič, L., Novak, P., Kovačič, J. y Avsec, A. (2011). Self-reported emotional and social intelligence and empathy as distinctive predictors of narcissism. Psychological Topics, 20(3), 477-488. Recuperado dehttps:// hrcak.srce.hr/78734

Eccles, S., Devis, C. y Mayer, M. (2017). Developing Socio-Emotional Intelligence in first year higher education student through one-to-one learning development tutorials. Journal of Learning Development in Higher Education, 12, 1-21. Recuperado de http://journal.aldinhe.ac.uk/index.php/jldhe/article/view/389

Extremera, N. (2003). El modelo de inteligencia emocional de Mayer y Salovey y su validez predictiva en muestras españolas (Tesis de doctorado). Universidad de Málaga, España. Recuperado de https://dialnet.unirioja.es/serv let $/$ tesis? codigo $=217388$

Extremera, N., Durán, A. y Rey, L. (2007). Inteligencia emocional y su relación con los niveles de burnout, engagement y estrés en estudiantes universitarios. Revista de educación, (342), 239-256. Recuperado dehttps:// bit.ly/2Tz46lQ

Extremera, N. y Fernández, P. (2002). La evaluación de la inteligencia emocional en el aula como factor protector de diversas conductas problema: violencia, impulsividad y desajuste emocional. En F. A. Muñoz, B. Molina y F. Jiménez (Eds.), Actas del I Congreso Hispanoamericano de Educación y Cultura de Paz (pp. 599-605). Granada: Universidad de Granada. Recuperado de http://emotional.intelligence.uma.es/pdfs/cultura\%20de\%20paz.pdf

Extremera, N. y Fernández, P. (2004). El papel de la inteligencia emocional en el alumnado: evidencias empíricas. Revista Electrónica de Investigación Educativa, 6. Recuperado de https://bit.ly/335xdQA

Extremera, N. y Fernández, P. (2005). Inteligencia emocional percibida y diferencias individuales en el metaconocimiento de los estados emocionales: una revisión de los estudios con el TMMS. Ansiedad y estrés, 11(2-3), 101-122. Recuperado de https://bit.ly/38uTnwY

Extremera, N. y Fernández, P. (2006). Emotional intelligence as predictor of mental, social, and physical health in university students. The Spanish journal of psychology, 9(1), 45-51. Recuperado de https://bit.ly/3aEYA6L

Extremera, N., Fernández, P., y Durán, A. (2003). Inteligencia emocional y burnout en profesores. Encuentros en psicología social, 1(5), 260-265. Recuperado de http://emotional.intelligence.uma.es/documentos/PDF5burno ut_en_profesores.pdf

Fernández, P. y Extremera, N. (2004). Inteligencia emocional, calidad de las relaciones interpersonales y empatía en estudiantes universitarios. Clínica y Salud, 15(2), 117-137. Recuperado de https://www.redalyc.org/pdf/1806 /180617822001.pdf

Fernández, P. y Ruíz, D. (2008). Emotional intelligence in education. Electronic Journal of Research in Educational Psychology, 6(15), 421-436. Recuperado de https://bit.ly/39Cso3N

Fernández, I., López, B. y Márquez, M. (2008). Empathy: measures, theories and applications under review. Anales de Psicologia/Annals of Psychology, 24(2), 284-298. Recuperado de https://revistas.um.es/analesps/article/view /42831 
Gardner, H. (1983). Frames of Mind: The theory of Multiple Intelligences. New York: Basis Books. Recuperado de ht tps://bit.ly/2VXLoWE

Goleman, D. (1996). La inteligencia emocional. Barcelona: Kairós.Recuperado de https://dialnet.unirioja.es/servlet/ articulo?codigo $=6289522$

Gómez, D., Mendoza, R., Paino, S. y de Matos, M. (2017). Perceived emotional intelligence as a predictor of depressive symptoms during mid-adolescence: A two-year longitudinal study on gender differences. Personality and individual differences, 104, 303-312. doi: https://doi.org/10.1016/j.paid.2016.08.022

Kwan, E., MacLeod, S., Chandler, M. y Fox, T. (2017). Report on a literature review of reforms related to the 2006 European Framework of Key Competences for lifelong learning and the role of the Framework in these reforms. European Commission. Recuperado de https://bit.ly/2Ixsj5F

Mayer, J. D., y Salovey, P. (1997). What is emotional intelligence? En P. Salovey y D. Sluyter (Eds), Emotional Development and Emotional Intelligence: Implications for Educators (pp. 3-31). Nueva York. Recuperado de ht tps://bit.ly/333JBAI

Mestre, M., Samper, P. y Frías, M. (2002). Cognitive and emotional processes as predictors of pro-social behaviour and aggressive conduct: empathy as a modulating factor. Psicothema, 14(2), 227-232. Recuperado de https://w ww.redalyc.org/pdf/727/72714207.pdf

Ministerio de Educación y Ciencia de España (2007). Boletín Oficial del Estado, 29 de diciembre de 2007, núm. 312.

Palomera, R., Fernández, P. yBrackett, M.(2008). Emotional intelligence as a basic competency in pre-service teacher training: Some evidence. Electronic Journal of Research in Educational Psychology, 6(15), 437-454. Recuperado de https://bit.ly/3azWZiy

Pena, M., y Extremera, N. (2012). Inteligencia emocional percibida en el profesorado de Primaria y su relación con los niveles de burnout e ilusión por el trabajo (engagement).Revista de Educación, (359), 604-627. Recuperado de https://bit.ly/2IygH2s

Pérez, A., De Paúl, J., Etxeberría, J., Montes, M. y Torres, E. (2003). Adaptación de Interpersonal ReactivityIndex (IRI) al español. Psicothema, 15(2), 267-272. Recuperado de https://josemariapoveda.com/images/irispanish.pdf

Pérez, C., Unguetti, A., Castillo, J. y Acosta, A. (2006). Inteligencia emocional e interferencia Stroop emocional en participantes con ansiedad rasgo elevada vs. baja. Ansiedad y estrés, 12(2), 251-265. Recuperado de https://dial net.unirioja.es/servlet/articulo?codigo $=2244264$

Salguero, J., Palomera, R. y Fernández, P. (2012). Perceived emotional intelligence as predictor of psychological adjustment in adolescents: a 1-year prospective study. European journal of psychology of education, 27(1), 21-34. doi: https://doi.org/10.1007/s10212-011-0063-8

Sánchez, M., Fernández, P., Montañés, J. y Latorre, J.(2008). Does emotional intelligence depend on gender? The socialization of emotional competencies in men and women and its implications. Electronic Journal of Research in Educational Psychology, 6(2), 455-474. Recuperado de https://bit.ly/2IxWGZI

Vinod, J., Srivastava, K. y Raychaudhuri, A. (2012). A Descriptive Study of Emotional Intelligence and Academic Performance of MBBS Students. Procedia-Social and Behavioral Sciences, 69, 2061-2067. doi: https://doi.org/ $10.1016 /$ j.sbspro.2012.12.165

\section{BY-NC-ND}

